\title{
Alternating sleeping arrangements as a coping strategy for snorers and their bed partners-A prospective study ${ }^{*}$
}

\author{
Stefan Seidel ${ }^{1,2 \#}$, Christian Wöber $^{2}$, Sabine Salhofer-Polanyi ${ }^{2}$, Doris Lieba-Samal ${ }^{2}$, \\ Eleonore Pablik ${ }^{3}$, Josef Zeitlhofer ${ }^{1}$, Gerhard Klösch ${ }^{1,2}$ \\ ${ }^{1}$ Institute for Sleep-Wake Research, Vienna, Austria; \\ \#Corresponding Author: stefan.seidel@meduniwien.ac.at \\ ${ }^{2}$ Department of Neurology, Medical University of Vienna, Vienna, Austria \\ ${ }^{3}$ Department of Medical Statistics, Medical University of Vienna, Vienna, Austria
}

Received 19 May 2013; revised 19 June 2013; accepted 15 July 2013

Copyright (C) 2013 Stefan Seidel et al. This is an open access article distributed under the Creative Commons Attribution License, which permits unrestricted use, distribution, and reproduction in any medium, provided the original work is properly cited.

\section{ABSTRACT}

Background: Despite overwhelming evidence for gender differences in sleep quality as well as gender-specific changes of sleep parameters with respect to habitual sleeping arrangements, studies on snorers and their bed partners have ignored the influence of individual quality of sleep as a potential co-factor. Objective: The objective of this study was to record subjective and objective sleep parameters and to analyze the effects of alternating of sleeping arrangements in snorers and their bed partners. Methods: Habitual snorers and their bed partners were recruited via newspaper articles not stating the exact purpose of the study. Both filled out a 90-day sleep diary. During this time, we recorded subjective and objective sleep parameters in the snorers and their bed partners via wrist actigraphy and sleep diaries for $\mathbf{1 4}$ days. For statistical analysis, we used two-sided t-tests and Spearman's Rho. Results: The dataset included 45 snorers ( 11 females) and 45 bed partners ( 34 females) with a mean age of $47 \pm 13$ and $43 \pm 12$ years. Screening for sleep apnea yielded snoring without OSAS, mild-, moderate- and severe OSAS in $27(60 \%)$, eight $(18 \%)$, three $(7 \%)$ and six $(15 \%)$ snorers. PSQI total scores were significantly lower in snorers than in bed partners ( $4 \pm 2$ vs. $6 \pm 4, p=0.002$ ). We could not find a significant correlation between subjective and objective sleep latency and efficiency. Couples

*Conflict of interest statement: The authors declare that there is no conflict of interest. who changed their sleeping arrangement were significantly younger than those who habitually slept alone or together $(p=0.01)$. Subjective sleep parameters of snorers or bed partners were not related to the number of consecutive nights spent either together or apart. Conclusions: Our study confirmed the weak correlation of subjective and objective sleep parameters in pairs with snoring problems. Couples changing their sleeping arrangement were the youngest among the whole group, but their separation of sleeping arrangements did not improve subjective sleep parameters.

Keywords: Snoring; Sleep Apnea; Bed Partners; Sleeping Arrangement; Actigraphy

\section{INTRODUCTION}

Pair sleep is common among adults and a recent survey in the United States showed that $61 \%$ of the respondents shared the bed with a partner. Nevertheless it is surprising, that given the dyadic nature of sleep for the majority of adults, a literature search from 1960 onwards only yielded five studies that had investigated the impact of different sleeping arrangements on sleep parameters [1]. In a polysomnographic study of fourteen married couples, Monroe found a significant increase in Stage 4 and a concomitant decrease in REM sleep when participants slept alone as compared to nights when they slept with their partner [2]. Despite the negative effects of pair sleep on sleep architecture, participants reported being less satisfied with their sleep when sleeping alone [2]. In a similar sense, Pankhurst and Horne found that couples 
reported better subjective sleep quality when they slept with the partner despite the actigraphic evidence showing more movements when participants slept with their partner [3].

In addition to the incongruency of subjective and objective sleep parameters, one might assume that the sexes react differently to sleeping arrangements [4]. Dittami et al. assessed pair sleep in healthy couples by means of actigraphy and found a negative effect on the sleep of women when sharing the bed with their male partners and reduced subjective sleep quality in men when sleeping alone [4].

Clinically women report poorer sleep quality despite their longer sleep duration [5]. But in contrast to these subjective data, studies based on polysomnography, show less wakefulness after sleep onset and higher amounts of slow wave sleep compared to men [5]. Women are also more reactive to movements of the bed partners [4] and more sensitive to interpersonal stressors, specifically negative daytime interactions [6]. All of these factors can contribute to higher rates of sleep disorders in women [4]. Individuals with insomnia show a tendency to pay more attention to stimuli in their internal and external environment [7]. Loud breathing noises and snoring are very common irritating factors for spouses [8].

Sharing the bed with a (male) snorer seems to be common [9], since roughly two thirds of respondents in a US telephone poll reported that their bed partner snored. Bed partners of habitual snorers frequently complained about disturbed sleep and relationship difficulties. Virkkula et al. [10] reported that in habitual snorers, approximately $50 \%$ of their bed partners were disturbed by snoring every night or almost every night. In a questionnaire based study [8] women who regularly slept with a heavy snorer reported symptoms of insomnia, morning headache, daytime sleepiness, and fatigue at higher rates than women of non-snorers. Moreover, one third of bed partners with heavy snorers reported disharmony in their relationship [3].

Sleeping apart may be used as a coping strategy by couples to improve their sleep quality [11]. In a telephone poll $31 \%$ of the respondents living with a snorer habitually slept in a separate bedroom or used earplugs [9]. Prospective data on sleep parameters in habitual snorers and their bed partners are limited and mostly confined to comparisons to single nights $[12,13]$. Simultaneous polysomnography in 16 couples of male habitual snorers and females during common and separated nights showed an increased time spent in non-REM stage 2 sleep and a decreased awakening index in bed partners when they slept alone [13]. It seems noteworthy, that the studied couples were instructed whether to sleep together or apart, and thus could not practice their usual sleeping arrangement. Moreover, we still do not know how many nights are necessary to consolidate the lack of sleep quality in spouses of snorers, when sleeping apart. It has been speculated that just a single night spent in a separate bedroom might not be sufficient to do the trick. Thus, changes in a sleeping arrangement themselves must be considered, and might exert effects in a time-dependent fashion.

To summarize, the influence of sleeping arrangements on both subjective and objective sleep parameters was examined in healthy couples $[3,14]$ and in couples of habitual snorers $[12,13]$. A specific limitation of the published data is that study participants were not monitored in a "field study" without instructions regarding their sleeping arrangements. Previous studies did not record sleep parameters over a prolonged period of time, although it is assumed that the accommodation to a new sleeping place takes longer than a single night to become noticeable.

To improve the lack of data on pair sleep in snorers and their bed partners we performed actigraphic recordings of the habitual snorers for 14 consecutive days. Since the couples were originally recruited for a prospective diary study on morning headaches [15] we also had the opportunity to analyze data of 90-day-sleep diary entries of each participant. In this hypothesis-generating study we postulate that changes in the sleeping arrangement result in positive effects on sleep efficiency and sleep latency of bed partners in a time-dependent fashion.

\section{PATIENTS AND METHODS}

Between January 2009 and May 2011 habitual snorers and their bed partners were recruited via newspaper advertisements for a large study aiming to investigate neuropsychiatric comorbidities in snorers and their partners [15]. The study protocol was approved by the Ethics Committee of the Medical University of Vienna, and written informed consent was obtained from each study participant prior to study inclusion.

Snorers and bed partners had to be between 18 und 75 years old and they should be able to fill out the study questionnaires and sleep diary. Exclusion criteria for snorers and bed partners were shift work, regular intake of sleep promoting substances, deafness or regular use of earplugs during sleep, substance addiction, severe respiratory disorders and other medical or psychiatric conditions.

At first visit, the snorers and their bed partners underwent a semi-structured interview and completed baseline questionnaires covering demographic characteristics and general medical history. Snorers and bed partners were provided with a 90-day diary including instructions how to use it. In addition, appointments were made for ambulant apnea screening in snorers and simultaneous wrist 
actigraphy in snorers and bed partners.

During the semi-structured interview height, weight, alcohol and tobacco intake, marital and employment status, physical exercise as well as medical and psychiatric history and current medication were assessed. Quality of sleep, daytime sleepiness and psychiatric co-morbidities were assessed using the Pittsburgh Sleep Quality Index (PSQI), the Epworth Sleepiness Scale (ESS), the Self-rating Anxiety Scale (SAS) and the Self-rating Depression Scale (SDS).

In the 90-day diary, patients and bed partners documented their sleeping arrangement (alone in a separate room or in the same bed), subjective sleep latency, sleep duration, quality of sleep (categories: "very bad", "bad", "good", "excellent") and reasons for disturbed sleep (based on free recall).

The PSQI assessed the quality and patterns of sleep in the four preceding weeks. It differentiated "poor" from "good" sleep in seven subsets: subjective sleep quality, sleep latency, sleep duration, habitual sleep efficiency, sleep disturbances, use of sleeping medication, and daytime dysfunction over the last four weeks. Scoring of answers was based on a 0 to 3 Likert scale, whereby 3 reflected the negative extreme. A total score of 5 or more indicated "poor" sleep [16].

The ESS is also a self-rating instrument to evaluate the tendency for dozing off during daytime. It consists of eight items of everyday situations. Reponses to each item were ranked from 0 to 3 according to the probability for dozing off during a task $(0=$ never, $1=$ low probability, 2 $=$ moderate probability, $3=$ high probability). A score $>$ 10 indicated excessive daytime sleepiness [17].

The SDS is a 20-item self-report measure of the symptoms of depression. Subjects rated each item according to how they felt during the preceding seven days. Item responses were ranked from 1 to 4 . The sum of the 20 items produced a score ranging between 20 and 80 , a cutoff value of $>40$ suggested clinically relevant depression [18].

The SAS measures affective and somatic symptoms of an anxiety disorder. The structure of the SAS is like that of the SDS. It also consisted of 20 questions, which referred to the last seven days. The result of the SAS was obtained by summing up the scores. A cut-off value of $>40$ suggested the presence of a clinically relevant anxiety disorder [19].

Snorers were screened for an Obstructive Sleep Apnea Syndrome (OSAS) using an ambulatory screening device ("Stardust ${ }^{T M}$ ", Respironics/Philips Medcare/Habel Medizintechnik, Vienna, Austria). OSAS was defined as an apnea/hypopnea index (AHI) $>5$ per hour/sleep (mild OSAS $=$ AHI $5-15$, moderate OSAS $=$ AHI $16-30$ and severe OSAS $=\mathrm{AHI}>30$ ). The Stardust ${ }^{T M}$ is a computer- ised ambulatory monitoring system for examining patients with suspected sleep apnea. The device records the following parameters: an airflow sensor for nasal air flow with snore measurement, a reusable piezo belt for the respiratory effort, a positional sensor for determination of supine or non-supine sleep position and $\mathrm{SAO}_{2}$ saturation with pulse rate. In particular, arterial oxyhemoglobin saturation und pulse rate are monitored by pulse oximetry with a sampling rate of $0.5 / \mathrm{s}$. The sleep period to be analyzed for the calculation of $\mathrm{RD} / \mathrm{AH}$ indexes was determined by the patient's sleep log as indicated in the computer-based scoring system of the device. Respiratory airflow was measured by a nasal pressure cannula (200 Hz sample rate). Snoring events were detected by pressure changes in the pressure cannula $(0.2$ $10 \mathrm{~Hz}$ sample rate). The sensitivity of the nasal pressure cannula (when connected to Stardust $I I^{\mathrm{TM}}$ ) was $0.06 \mathrm{~cm}$ $\mathrm{H}_{2} \mathrm{O}$ (mbar) in a range between -5 to $+5 \mathrm{~cm} \mathrm{H}_{2} \mathrm{O}$ (mbar).

The snore index was calculated by dividing the total number of snore events recorded by the hours of the analyzed period (light off-light on period). The oxygen desaturation index (ODI) was calculated by dividing the total number of desaturation events recorded by the hours of the analyzed period.

Besides AHI and ODI, the software of Stardust II $I^{\mathrm{TM}}$ (Windows ${ }^{\circledR}$-based application) automatically calculated the apnea index (AI) and the respiratory desaturation index (RDI). The system scored a "desaturation event" when $\mathrm{SaO}_{2}$ fell $<3 \%$ from baseline; the event lasts until $95 \%$ of baseline has been reached again. The maximum possible duration of the event was two minutes, while a desaturation of two minutes was not scored as an event. Baseline saturation was calculated with an algorithm on the basis of the two highest values in the last 40 s.

Sleep wake rhythm was monitored continuously over a period of 14 days/nights by actigraphs ("Actiwatch"TM activity monitors from Cambridge Neurotechnology Ltd., Cambridge, United Kingdom). The epoch length was set to a 30 -sec periods and subjects were instructed to wear the monitors on the wrist of the non-dominant hand, taking off the device only for bathing or showering. Collected data was analysed with Actiwatch Activity and Sleep Analysis Software 7.5 (Cambridge Neurotechnology Ltd., Cambridge, United Kingdom) and sleep latencies and sleep efficiency was calculated for all recorded nights.

Simultaneous to actigraphy, subjective sleep parameters were assessed by sleep diaries in snorers and bed partners. Couples did not receive any instructions regarding their sleeping arrangements, i.e. if they should sleep in the same room or in separate rooms, during the 14-day actigraphic observation period.

Couples were included in the final analysis if 1) sleep diaries from both the snorer and bed partner were avail- 
able, 2) entries regarding the sleeping arrangement (alone or together) were concordant and also present during the 14 days of actigraphy, 3) actigraphic data of both the snorer and bed partner were available.

For all calculations we used IBM SPSS Statistics for Windows (version 20.0) and $R$ (version 2.15.2). To detect differences between snorers' and bed partners' PSQI-, ESS-, SAS- and SDS-scores as well as objective sleep parameters data were analyzed using paired two-sided t-tests. Sleep latency and sleep efficiency were calculated from sleep log data as well as from actigraphic recordings (utilizing Actiwatch activity and Sleep Analysis Software 7.5). The Spearman correlation coefficient was calculated to check the correlation between subjective and objective data. To test the influence of sleeping arrangements on subjective data, a mixed model with a random factor for each patient was used. The level of significance was set at $\mathrm{p}<0.05$ for all tests. Unless stated otherwise, all values are presented as means \pm standard deviation (S.D.). Due to the hypothesis-generating character of the study no corrections for multiple testing was applied.

\section{RESULTS}

Forty-five (11 females) snorers and 45 (34 females) bed partners with a mean age of $47 \pm 13$ and $43 \pm 12$ years were included in this study. The Body Mass Index (BMI) did not differ significantly between snorers and bed partners $(28 \pm 3$ vs. $26 \pm 4, \mathrm{p}=0.7)$.

PSQI total scores were significantly lower in snorers than in bed partners ( $4 \pm 2$ vs. $6 \pm 4, p=0.002$ ) whereas ESS-, SDS-, and SAS total scores did not differ significantly between bed partners and snorers (ESS: $9 \pm 4$ vs. 7 $\pm 4, \mathrm{p}=0.2$; SDS: $35 \pm 10$ vs. $35 \pm 9, \mathrm{p}=0.4$; SAS: $33 \pm$ 10 vs. $36 \pm 9, \mathrm{p}=0.9$ )

Apnea screening data was not available in one patient due to technical problems. Apnea screening yielded snoring without-, mild-, moderate- and severe OSAS in $27(60 \%)$, eight $(18 \%)$, three $(7 \%)$ and six (15\%) patients.

We analyzed a total of 3.900 diary days (45 couples). Snorers and bed partners filled out a mean of $87 \pm 14$ days (range 15 to 93 days). Actigraphy was performed for a mean of $13 \pm 4$ days/nights (range eight to 23 days). Due to technical and participant-related problems we had to exclude several actigraphic data-sets. In total, final analysis comprises simultaneous actigraphic data of 606 (15.5\%) days in 45 couples.

\subsection{Subjective vs. Objective Sleep Parameters}

Sleep efficiencies (\%) and sleep onset latencies (minutes) were calculated for each subject over 14 nights by subjective estimates (sleep diaries) and objectively (based on actigraphy). Significant differences between patients and partners were only found in subjective sleep onset latencies (Tables 1 and 2). There was no correlation (Spearman's Rho) between subjective (sleep diaries) and objective (actigraphy) sleep efficiency and sleep latency (Figures 1(a) and (b)) in the overall sample and very poor correlations in each person. In the 45 couples a moderate or high correlation (Spearman correlation coefficient $>0.5$ ) occurred 13 times of which five were negative correlated and eight were positive correlated. Based on these statistical results we must assume that these were random positive/negative correlations.

\subsection{Sleep Arrangements and Sleeping Parameters}

The majority (31 out of 45) of the analyzed pairs changed their sleeping arrangement at least once during the observation period, eight always slept together and, six always preferred separate bedrooms. There was a significant difference in the mean age of couples with fixed sleeping arrangement (always together or always separated) and couples with changing sleeping arrangements (Figure 2, $\mathrm{p}=0.01$ ). No significant difference in

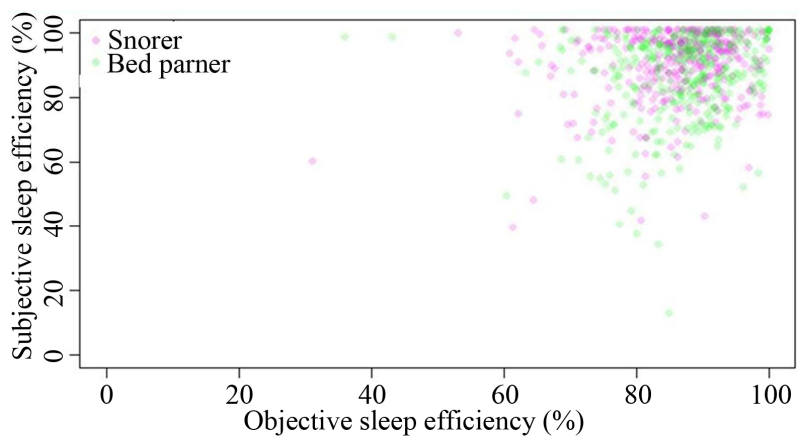

(a)

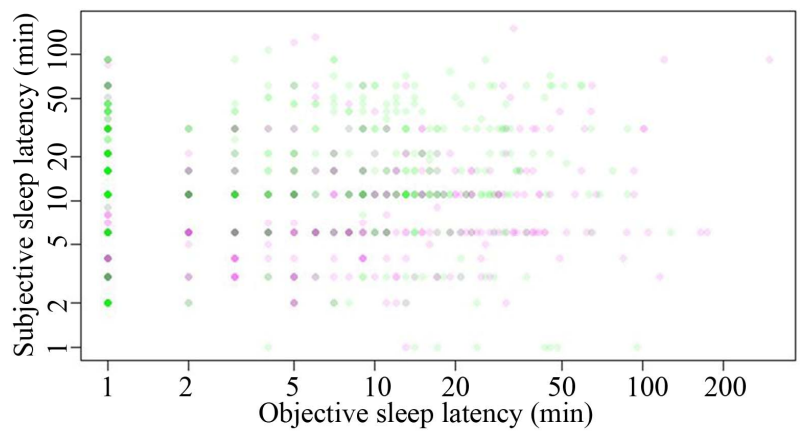

(b)

Figure 1. (a) Scatter plot showing the correlation between the subjective and objective sleep efficiency in snorers (purple dots) and their bed partners (green dots); (b) Scatter plot showing the correlation between the subjective and objective sleep latency in snorers (purple dots) and their bed partners (green dots). 
Table 1. Means, standard deviations and range (minimum/maximum) of subjective and objective sleep parameters (single nights) over 14 nights (with actigraphy) as well as over the whole observation period of 90 days.

\begin{tabular}{ccccc}
\hline & Mean \pm S.D. & Min-Max & Mean \pm S.D. & Min-Max \\
\hline Sleep efficiency (\%, actigraphy) & $85.7 \pm 8.4$ & $1-99.1$ & $84.10 \pm 8.86$ & $18.7-99.1$ \\
Sleep onset latency (minutes, actigraphy) & $10.8 \pm 23.2$ & $0-297$ & $9.8 \pm 15.2$ & $0-126$ \\
Subjective sleep efficiency (\%) & $89.3 \% \pm 10.5$ & $38.7-100$ & $86 \pm 13$ & $11.8-100$ \\
Subjective sleep onset latency (minutes) & $12.7 \pm 16.6$ & $0-150$ & $19.1 \pm 18.4$ & $0-105$ \\
Subjective sleep efficiency (\% over 90 days) & $90.4 \pm 10.5$ & $21.1-100$ & $86.9 \pm 11.9$ & $11.8-100$ \\
Subjective sleep onset latency (minutes over 90 days) & $11.2 \pm 16.3$ & $0-420$ & $17.7 \pm 18.6$ & $0-300$ \\
\hline
\end{tabular}

Table 2. Grand mean of subjective and objective sleep parameters (calculated from means over each subject) and the results of unpaired two-sided t-test. Significant differences are indicated by bold letters.

\begin{tabular}{|c|c|c|c|c|c|}
\hline & $\begin{array}{c}\text { Patients } \\
(\text { Mean } \pm \text { S.D. })\end{array}$ & $\begin{array}{l}\text { Significant } \\
\text { difference }\end{array}$ & $\begin{array}{c}\text { Partners } \\
(\text { Mean } \pm \text { S.D. })\end{array}$ & $\begin{array}{c}\text { Significant } \\
\text { difference }\end{array}$ & $\begin{array}{l}\text { Significant difference } \\
\text { (Patients/Partner) }\end{array}$ \\
\hline $\begin{array}{l}\text { Sleep efficiency } \\
(\% \text {, actigraphy) }\end{array}$ & $85.7 \pm 5.5$ & \multirow[b]{2}{*}{0.008} & $84.5 \pm 6.7$ & \multirow[b]{2}{*}{ n.s. } & 0.389 \\
\hline $\begin{array}{c}\text { Subjective sleep efficiency } \\
(\%)\end{array}$ & $89.2 \pm 6.6$ & & $85.9 \pm 9.9$ & & 0.132 \\
\hline $\begin{array}{l}\text { Sleep onset latency } \\
\text { (minutes, actigraphy) }\end{array}$ & $11 \pm 12.3$ & \multirow{2}{*}{ n.s. } & $9.6 \pm 7.4$ & \multirow{4}{*}{$<\mathbf{0 . 0 0 0}$} & 0.534 \\
\hline $\begin{array}{l}\text { Subjective sleep onset latency } \\
\text { (minutes) }\end{array}$ & $12.8 \pm 8.6$ & & $19.2 \pm 13.1$ & & 0.010 \\
\hline $\begin{array}{l}\text { Subjective sleep efficiency } \\
\text { (\% over } 90 \text { days) }\end{array}$ & $90.3 \pm 6.9$ & & $87.3 \pm 8.4$ & & 0.112 \\
\hline $\begin{array}{l}\text { Subjective sleep onset latency } \\
\text { (minutes over } 90 \text { days) }\end{array}$ & $11.3 \pm 6.3$ & & $18.6 \pm 12.6$ & & 0.001 \\
\hline
\end{tabular}

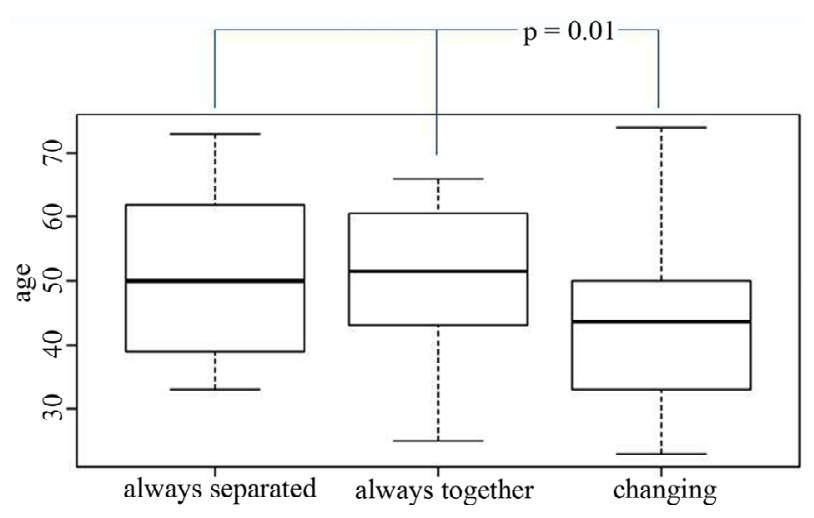

Figure 2. Box plot showing the mean ages of couples (from left to right) who always slept apart, always slept together or changed their sleeping arrangement in varying degrees.

the sleeping arrangements depending on the sex of the snorer could be found ( $p=0.6$ ). On average, couples changed their sleeping arrangement 6.6 times (range 0 to 40 times). The time span of unchanged sleeping arrangement ranged between nine and 90 days with a mean of 46 days.

Subjective sleep efficiency in snorers (Figures 3(a) and (b)) and bed partners (Figures 3(c) and (d)) did not change significantly with respect to the number of con- secutive nights spent apart (Figures 3(a) and (c)) or in the same bed (Figures 3(b) and (d)). The same was true for the subjective sleep onset latency (data not shown). Testing for significant differences between the days (including a random factor for each person in order to adjust for repeated measurements) showed no significant result, even though no correction for multiple testing was applied. Unfortunately, objective sleep parameters could not be analyzed in this fashion, given that the majority of couples did not change their sleeping arrangements during the period of actigraphy.

\section{DISCUSSION}

This is the first study that prospectively assessed subjective and objective sleep parameters in habitual snorers and their non-snoring bed partners over a prolonged period of time with respect to their sleeping arrangements. The main findings were that 1) subjective and objective sleep parameters were only weakly correlated and 2) subjective sleep parameters in both groups did not change significantly with respect to the number of consecutive nights spent either apart or in the same bedroom.

Approximately three quarters of our habitual snorers 


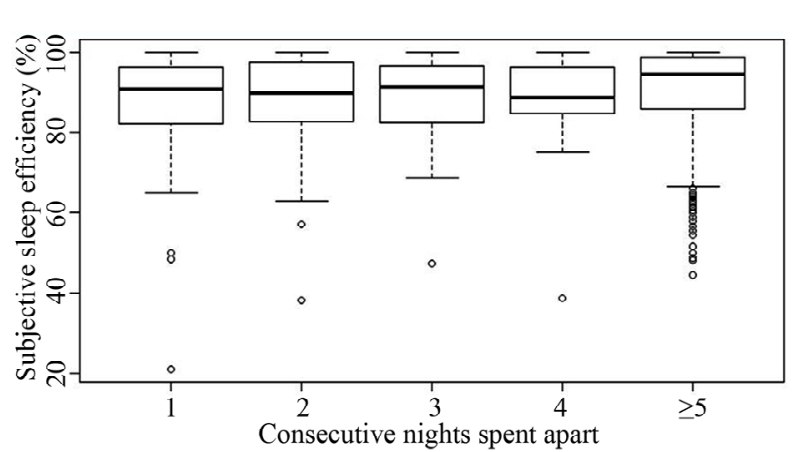

(a)

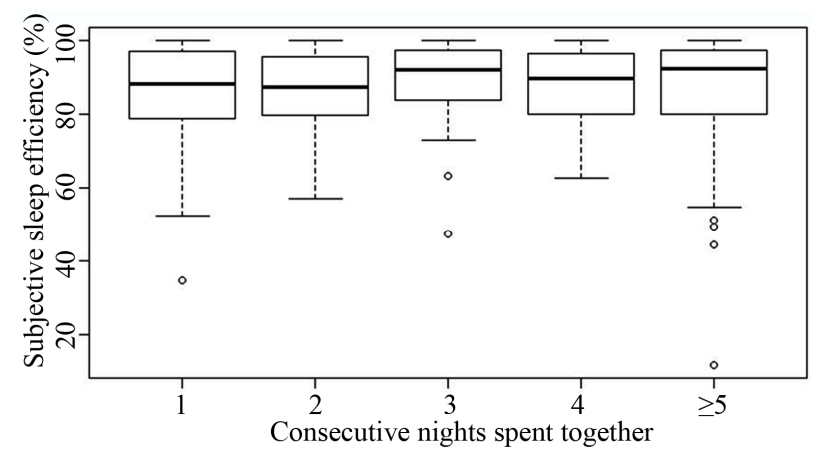

(c)

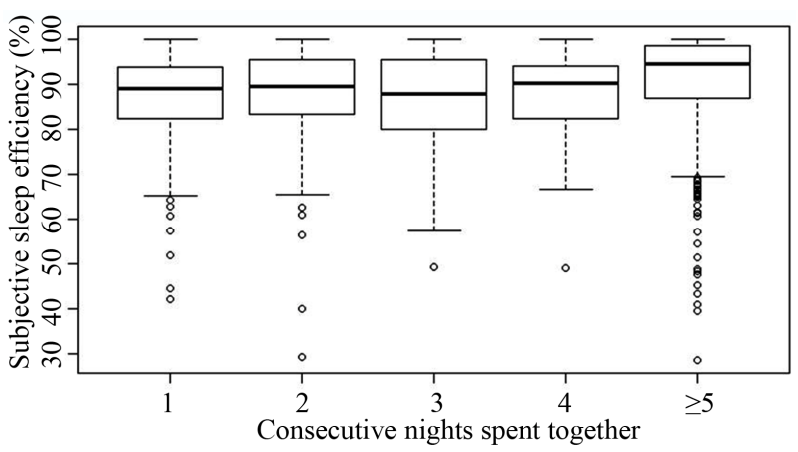

(b)

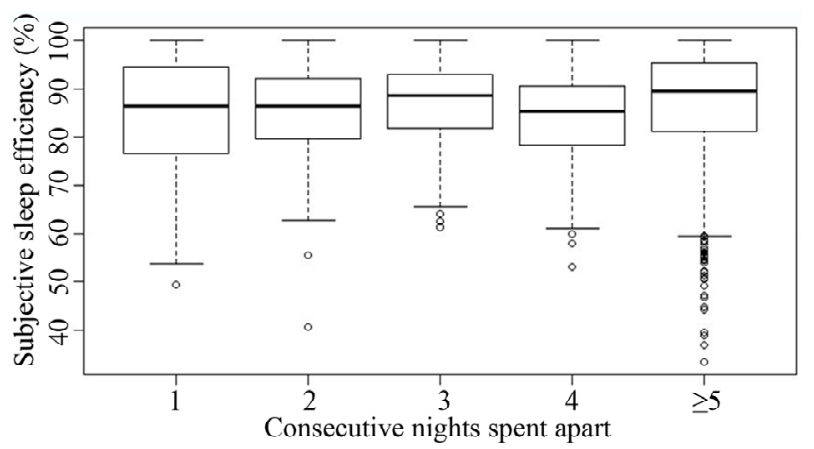

(d)

Figure 3. (a) Box plot showing the subjective sleep efficiency of snorers, dependent of the number of consecutive nights spent in separate bedrooms (five and more nights are pooled in block 5). Numbers at the X axis indicate the consecutive nights spent apart. Small circles indicate spikes; (b) Box plot showing the subjective sleep efficiency of snorers, dependent of the number of consecutive nights spent in the same bedroom (five and more nights are pooled in block 5). Numbers at the $\mathrm{X}$ axis indicate the consecutive nights spent together. Small circles indicate spikes; (c) Box plot showing the subjective sleep efficiency of bed partners, dependent of the number of consecutive nights spent in separate bedrooms (five and more nights are pooled in block 5). Numbers at the X axis indicate the consecutive nights spent apart. Small circles indicate spikes; (d) Box plot showing the subjective sleep efficiency of bed partners, dependent of the number of consecutive nights spent in the same bedroom (five and more nights are pooled in block 5). Numbers at the $\mathrm{X}$ axis indicate the consecutive nights spent together. Small circles indicate spikes.

were men and of these, forty percent met the sleep disturbance criteria of OSAS (i.e. AHI > 5). These findings are in line with the results from a population-based study on the prevalence of sleep-disordered breathing [20]. In our sample, $13 \%$ of all couples habitually slept alone, which matched the results Doherty et al. [21], reporting that $18 \%$ of partners of OSAS patients waiting for CPAP titration preferred separate bedrooms. In contrast to a previous study [21] we could rule out anxiety or depression as confounding factors for the choice of sleeping arrangements, since snorers and bed partners did not differ regarding SAS- or SDS-scores. To summarize, in our sample with predominantly male snorers, subjective sleep quality was significantly worse in non-snoring partners than in snorers. Besides the fact that snoring and OSAS were "conditions of the listeners" [22] and therefore disturbed the sleep of the bed partners, men usually reacted to pair sleep as if it were a group sleep condition and sleep better [4].

Up to now, only one study had examined sleeping arrangements in snorers and their bed partners, i.e. sleep- ing in the same bed and sleeping in separate bedrooms [12]. The authors concluded, that bed partners seemed to benefit objectively from sleeping alone [12], which is not supported by our findings. Based on our prospective design we also had the opportunity to check if sleep parameters gradually improved over time after a new sleeping arrangement had been established. We failed to observe any significant changes here and hence assume, that recovering after exposure to sleep-disturbing stimuli may even take much longer than had been previously assumed [23].

The poor correlation between subjective and objective sleep parameters has previously been reported [11]. Among other factors (e.g. duration and frequency of nights with non restorative sleep) also psychological and biographical parameters (e.g. connotations associated with poor sleep) are discussed to explain this phenomenon.

Since our study design did not force couples to choose a certain sleeping arrangement, data analyses were limited by a non equal distribution of nights with/without a 
partner. Other limitations of our study have to be mentioned. Bed partners were not screened for OSAS. The ESS score has been found to rise with increasing frequency of snoring and sleep-disordered breathing in middle-aged and older adults [21]. The mean total ESS score in our bed partners was comparable to the mean ESS total score in snorers without OSAS.

Sleep disruption in bed partners would have been more pronounced, if we had included more snorers with moderate to severe OSAS. A larger sample of couples might have enabled us to detect more subtle differences regarding sleep parameters, but the clinical significance of such results remains unclear. We did not include a control group of couples without habitual snorers.

Marital quality was also not assessed. Previous studies that had focused on sleep and the quality of the relationship had found a moderate to strong association between martial satisfaction and good sleep quality $[6,24]$.

Our study was strengthened by its prospective design, the long observation period and the simultaneous recording of sleep parameters in the couples.

In conclusion, frequent changes in sleeping arrangement are not common in couples with habitual snorers and a non-snoring bed partner and only a small number of couples decided not to share their bedroom. Moreover, separated bedrooms did not yield any benefit regarding sleep latency or efficiency neither for the snoring- nor for the non-snoring partner.

\section{ACKNOWLEDGEMENTS}

The authors would like to express their thanks to Prof. J.P. Dittami for editorial assistance. The authors would also like to thank the Institute for Sleep-Wake Research for its financial support regarding the publication of this manuscript.

\section{REFERENCES}

[1] Troxel, W.M., Robles, T.F., Hall, M. and Buysse, D.J. (2007) Marital quality and the marital bed: Examining the covariation between relationship quality and sleep. Sleep Medicine Reviews, 11, 389-404. doi:10.1016/j.smrv.2007.05.002

[2] Monroe, L.J. (1969) Transient changes in EEG sleep patterns of married good sleepers: The effects of altering sleeping arrangement. Psychophysiology, 6, 330-337. doi:10.1111/j.1469-8986.1969.tb02910.x

[3] Pankhurst, F.P. and Horne, J.A. (1994) The influence of bed partners on movement during sleep. Sleep, 17, 308315 .

[4] Dittami, J., Keckeis, M., Machatschke, I., Katina, S., Zeitlhofer, J. and Klösch, G. (2007) Sex differences in the reactions to sleeping in pairs versus sleeping alone in humans. Sleep and Biological Rhythms, 5, 271-276. doi:10.1111/j.1479-8425.2007.00320.x

[5] Manber, R. and Armitage, R. (1999) Sex, steroids, and sleep: A review. Sleep, 22, 540-555.

[6] Hasler, B.P. and Troxel, W.M. (2010) Couples' nighttime sleep efficiency and concordance: Evidence for bidirectional associations with daytime relationship functioning. Psychosomatic Medicine, 72, 794-801. doi:10.1097/PSY.0b013e3181ecd08a

[7] Harvey, A.G. (2002) A cognitive model of insomnia. Behaviour Research and Therapy, 40, 869-893. doi:10.1016/S0005-7967(01)00061-4

[8] Ulfberg, J., Carter, N., Talback, M. and Edling, C. (2000) Adverse health effects among women living with heavy snorers. Health Care for Women International, 21, 81-90. doi:10.1080/073993300245311

[9] Hiestand, D.M., Britz, P., Goldman, M. and Phillips, B. (2006) Prevalence of symptoms and risk of sleep apnea in the US population: Results from the national sleep foundation sleep in America 2005 poll. Chest, 130, 780-786. doi:10.1378/chest.130.3.780

[10] Virkkula, P., Bachour, A., Hytonen, M., Malmberg, H., Salmi,T. and Maasilta, P. (2005) Patient- and bed partnerreported symptoms, smoking, and nasal resistance in sleep-disordered breathing. Chest, 128, 2176-2182. doi:10.1378/chest.128.4.2176

[11] Means, M.K., Edinger, J.D., Glenn, D.M. and Fins, A.I. (2003) Accuracy of sleep perceptions among insomnia sufferers and normal sleepers. Sleep Med. 4, 285-296. doi:10.1016/S1389-9457(03)00057-1

[12] Blumen, M., Quera Salva, M.A., d'Ortho, M.P., Leroux, K., Audibert, P., Fermanian, C., Chabolle, F. and Lofaso, F. (2009) Effect of sleeping alone on sleep quality in female bed partners of snorers. European Respiratory Journal, 34, 1127-1131. doi:10.1183/09031936.00012209

[13] Blumen, M.B., Quera-Salva, M.A., Vaugier, I., Leroux, K., d'Ortho, M.P., Barbot, F., Chabolle, F. and Lofaso, F. (2012) Is snoring intensity responsible for the sleep partner's poor quality of sleep? Sleep and Breathing, 16, 903907. doi:10.1007/s11325-011-0554-5

[14] Meadows, R., Venn, S., Hislop, J., Stanley, N. and Arber, S. (2005) Investigating couples' sleep: An evaluation of actigraphic analysis techniques. Journal of Sleep Research, 14, 377-386. doi:10.1111/j.1365-2869.2005.00485.x

[15] Seidel, S., Frantal, S., Oberhofer, P., Bauer, T., Scheibel, N., Albert, F., Pacher, J., Casjens, T., Klösch, G., Zeitlhofer, J. and Wöber, C. (2012) Morning headaches in snorers and their bed partners: A prospective diary study. Cephalalgia, 32, 888-895. doi: $10.1177 / 0333102412453950$

[16] Buysse, D.J., Reynolds III, C.F., Monk, T.H., Berman, S.R. and Kupfer, D.J. (1989) The Pittsburgh sleep quality index: A new instrument for psychiatric practice and research. Psychiatry Research, 28, 193-213. doi:10.1016/0165-1781(89)90047-4

[17] Johns, M.W. (1991) A new method for measuring daytime sleepiness: The Epworth sleepiness scale. Sleep, 14, 540545.

[18] Zung, W.W. (1965) A self-rating depression scale. Archives of General Psychiatry, 12, 63-70. 
doi:10.1001/archpsyc. 1965.01720310065008

[19] Zung, W.W. (1976) SAS, Self-rating anxiety scale. In: Guy, W., Ed., ECDEU Assessment Manual for Psychopharmacology, Rockville, 337-340.

[20] Young, T., Palta, M., Dempsey, J., Skatrud, J., Weber, S. and Badr, S. (1993) The occurrence of sleep-disordered breathing among middle-aged adults. The New England Journal of Medicine, 328, 1230-1235. doi:10.1056/NEJM199304293281704

[21] Doherty, L.S., Kiely, J.L., Lawless, G. and McNicholas, W.T. (2003) Impact of nasal continuous positive airway pressure therapy on the quality of life of bed partners of patients with obstructive sleep apnea syndrome. Chest, 124, 2209-2214. doi:10.1378/chest.124.6.2209

[22] Stalkrantz, A., Brostrom, A., Wiberg, J., Svanborg, E. and
Malm, D. (2012) Everyday life for the spouses of patients with untreated OSA syndrome. Scandinavian Journal of Caring Science, 26, 324-332. doi:10.1111/j.1471-6712.2011.00937.x

[23] Walsleben, J.A., Kapur, V.K., Newman, A.B., Shahar, E., Bootzin, R.R., Rosenberg, C.E., O'Connor, G. and Nieto, F.J. (2004) Sleep and reported daytime sleepiness in normal subjects: The Sleep Heart Health Study. Sleep, 27, 293-298.

[24] Troxel, W.M., Buysse, D.J., Hall, M. and Matthews, K.A. (2009) Marital happiness and sleep disturbances in a multi-ethnic sample of middle-aged women. Behavioral Sleep Medicine, 7, 2-19. doi:10.1080/15402000802577736 